\title{
Reference Values of Urinary Neutrophil Gelatinase-Associated Lipocalin in Very Low Birth Weight Infants
}

\author{
TRANG K. HUYNH, DAVID A. BATEMAN, ELVIRA PARRAVICINI, JOHN M. LORENZ, SHERI L. NEMEROFSKY, \\ MEGHAN E. SISE, TERESA M. BOWMAN, ELENA POLESANA, AND JONATHAN M. BARASCH
}

\author{
Department of Pediatrics [T.K.H.], New York Presbyterian Hospital-Weill Cornell Medical College, New York, New York 10065; \\ Departments of Pediatrics [D.A.B., E.P., J.M.L., T.M.B., E.P.] and Medicine [M.E.S., J.M.B.], Columbia University, New York, New York \\ 10032; Department of Pediatrics [S.L.N.], Albert Einstein College of Medicine/Montefiore Medical Center, Bronx, New York 10461
}

\begin{abstract}
In very low birth weight (VLBW) infants, acute renal impairment (ARI) is common, but there is no consensus about criteria for its diagnosis. Neutrophil gelatinase-associated lipocalin (NGAL) is an early and sensitive indicator of renal impairment in experimental animals, children, and adults. Urinary NGAL (UNGAL) is detectable in VLBW infants; however, there is no reference range in this population. The objective of this study is to define the reference range for UNGAL in VLBW infants with no risk factors for acute renal impairment. UNGAL concentration was determined in urine samples collected from day of life (DOL) 4 through DOL 30 in 50 newborns with uncomplicated clinical courses, selected from a total of 145 prospectively enrolled appropriate for gestational age inborn VLBW premature infants. The birth weight and gestational age ranges were 790-1490 g and 26-33 wk, respectively. The median, 95th and 99th percentiles, and range of pooled UNGAL values were $5 \mathrm{ng} / \mathrm{mL}, 50 \mathrm{ng} / \mathrm{mL}, 120 \mathrm{ng} / \mathrm{mL}$, and $2-150 \mathrm{ng} / \mathrm{mL}$, respectively. Greater variability and higher quantile levels of UNGAL were observed in females versus males. In conclusion, a reference range for UNGAL in VLBW infants, similar to that in children and adults, has been established. (Pediatr Res 66: 528-532, 2009)
\end{abstract}

$I^{\mathrm{n}}$ older children and adults, serum creatinine concentration ([SCreat]) has been widely used as a marker of glomerular filtration rate (GFR) and, thus, of acute renal impairment (ARI). In the very low birth weight (VLBW) infant, however, renal impairment cannot be defined by an absolute value of [SCreat]. [SCreat] initially reflects maternal creatinine concentration. The ultimate steady-state value of [SCreat] and the time required to reach it are related to infant muscle mass and GFR, both of which are inversely related to gestational age. In VLBW infants with normal renal function, [SCreat] increases during the first 3-5 d of life, then declines slowly over the next few weeks to reach a steady state. Thus, when the diagnosis of renal impairment is based on [SCreat] rather than measurement of GFR, renal impairment must be defined as an abnormal change in [SCreat] for gestational and postnatal age (1-4). [SCreat] is also relatively insensitive to acute changes in renal function and is a poor early marker of ARI. These

Received March 17, 2009; accepted July 17, 2009.

Correspondence: Trang K. Huynh, M.D., Division of Newborn Medicine, Department of Pediatrics, New York Presbyterian Hospital-Weill Cornell Medical College, 525 East 68th Street, N-506, New York, New York 10065; e-mail: trangkhuynh@yahoo.com

Supported by Grant UL1 RR024156 from the National Center for Research Resources; Grants DK-55388 and DK-58872 from the National Institute of Diabetes and Digestive and Kidney Diseases (J.B.); and grants from the Emerald Foundation and the March of Dimes. complexities in the interpretation of [SCreat] values have led to the search for an acutely sensitive, more easily interpreted indicator of renal impairment in VLBW infants.

Hypotension, hypovolemia, hypoxemia, perinatal asphyxia, and acidosis can cause ARI, as can complications of mechanical ventilation, umbilical artery/vein catheterization, and the administration of vasoactive or nephrotoxic medications (57). Sequelae of intrinsic ARI include chronic renal failure, glomerular and/or tubular dysfunction, cortical scarring or atrophy, papillary necrosis, nephrocalcinosis, arterial hypertension, and impaired renal growth (6). Prevention of associated morbidity and mortality depends upon the rapid diagnosis of ARI and prompt treatment of the underlying cause(s).

Neutrophil gelatinase-associated lipocalin (NGAL) has been shown to be a sensitive, early indicator of intrinsic renal failure in experimental animals, children, and adults. NGAL is a $25 \mathrm{kD}$ protein member of the lipocalin family of proteins. NGAL exists in two separate body pools-a systemic pool and a renal pool $(8,9)$. In the systemic pool, NGAL is normally expressed at very low concentrations in many organs, as well as in neutrophils and macrophages. NGAL expression is up-regulated by infection, inflammation, ischemia, and neoplastic transformation. NGAL may also serve an important anti-bacterial function by competing for iron, an important bacterial nutritional requirement (10). Circulating NGAL is captured by megalin in the proximal tubule; thus, very little $(0.1-0.2 \%)$ is found in urine.

Urinary neutrophil gelatinase-associated lipocalin (UNGAL), representing the renal pool, consists of NGAL produced by the renal tubules, not filtered NGAL. UNGAL production is upregulated acutely in the thick ascending limb of Henle and collecting ducts in the postischemic kidney in mouse models $(8,9)$. Importantly, UNGAL has been shown to be an early marker of acute intrinsic renal injury due to ischemia and nephrotoxins in animal models (11-14), after cardiopulmonary bypass and renal transplantation in adults and children (15-18), and during the acute phases of kidney injury associ-

Abbreviations: ARI, acute renal impairment; DOL, day of life; GFR, glomerular filtration rate; NGAL, neutrophil gelatinase-associated lipocalin; [SCreat], serum creatinine concentration; UNGAL, urinary neutrophil gelatinase-associated lipocalin; VLBW, very low birth weight 
ated with contrast administration, hemolytic-uremic syndrome, and lupus nephritis (19-21).

NGAL has also been shown to play an important role in kidney development. In embryonic rodent kidneys, it is expressed by the ureteric bud and stimulated by hepatocyte growth factor. NGAL, in association with iron, is sufficient for the conversion of mesenchymal cells into tubular epithelial cells, having promigratory and probranching effects. Suppression of NGAL expression results in increased cyst formation by tubular cells in vitro (22-24).

It is of interest to know whether UNGAL may also be an early indicator of renal impairment in the premature infant, given the difficulties of making this diagnosis. However, the UNGAL reference range in VLBW neonates has not been defined. Its role in renal development raises the possibility that the reference range in premature infants may differ from that in adults and children. In a previous article involving 22 VLBW infants with uncomplicated clinical courses, a preliminary reference range of UNGAL concentration was established based on urine samples collected weekly (25). By adding a larger number of infants with daily urine collections to this initial group, this study aims to refine the reference range for UNGAL concentration in VLBW infants who have uncomplicated clinical courses and no risk factors for ARI and to determine whether this reference range varies with gestational and/or postnatal age.

\section{METHODS}

Subjects. This is a prospective observational study involving 145 inborn premature newborns delivered between September 2005 and June 2006 (period 1) and between March 2007 and March 2008 (period 2). During period 1, all infants were born at Morgan Stanley Children's Hospital of New York-Presbyterian (MSCHONY) and during period 2 either at MSCHONY or at Albert Einstein College of Medicine/Montefiore Medical Center (AE$\mathrm{COM}$ ). Inclusion criteria were birth weight $\leq 1500 \mathrm{~g}$ and birth weight appropriate for gestational age. Infants with major congenital anomalies or abnormal karyotypes were excluded. Parental consent for study participation was solicited during the first $3 \mathrm{~d}$ of life. The Institutional Review Boards of MSCHONY and AECOM approved this study.

Of 145 infants enrolled in the study, 50 (20 during period 1 and 30 during period 2) had uncomplicated clinical courses. An uncomplicated clinical course was defined by absence of the following conditions: prenatal maternal ACE inhibitor or indomethacin therapy; perinatal asphyxia resulting in base excess more negative than $-10 \mathrm{mM}$ within the first $12 \mathrm{~h}$ of life; grade $3 / 4$ intracranial hemorrhage (IVH); $\mathrm{FiO}_{2}$ requirement $\geq 50 \%$ beyond $48 \mathrm{~h}$ age or mechanical ventilation at any age; clinical sepsis (consistent signs plus treatment with antibiotics $\geq 5 \mathrm{~d}$ ) or culture (blood, CSF, or urine) proven infection; NEC (pneumatosis intestinalis on x-ray or surgical confirmation); therapy with indomethacin, ibuprofen, or amphotericin; any surgery; renal impairment [for infants $\geq 27$-wk gestation, a sustained ( $48 \mathrm{~h}$ ) increase in [SCreat] $\geq 0.3 \mathrm{mg} / \mathrm{dL}$ at any point; for infants $<27$-wk gestation, a $>0.3$ $\mathrm{mg} / \mathrm{dL}$ rise in [SCreat] during day of life (DOL) $1-4$ or a sustained $(48 \mathrm{~h})$ increase in [SCreat] $\geq 0.3 \mathrm{mg} / \mathrm{dL}$ on $\geq$ DOL 5]; or patent ductus arteriosus requiring treatment. Furosemide, if used, was given only as a single dose after blood transfusions. Although brief episodes of self-limited apnea/bradycardia/ desaturation were common in many of these infants, none of them required intervention with positive pressure ventilation. Echocardiograms were performed at entry and then weekly to evaluate for patent ductus arteriosus by a neonatologist (EP, SLN) and reviewed by a pediatric cardiologist. Adjudication of infants who qualified as having an uncomplicated clinical course was performed by a team that included two neonatologists and a neonatal fellow (EP, JML, TKH) who were blinded to UNGAL measurements. [SCreat] was determined according to the clinical needs of each infant: frequency ranged from daily to weekly. In all, there were 450 [SCreat] determinations between days 4 and 30 for the 50 infants with uncomplicated clinical courses.

Urine collection and UNGAL analysis. A total of 706 bagged urine samples were obtained prospectively from 50 newborns with uncomplicated courses, starting on DOL 4 and continuing through DOL 30. During period 1, a total of 75 urine samples were collected weekly, and during period 2, a total of 631 urine samples were collected daily. The percent collection yield (actual number of specimens collected/number expected) was $75 \%$ (75/100) during period 1 and $75 \%(631 / 840)$ during period 2 . Collection yield was higher for males (74\% overall) compared with females (70\% overall), but the difference in these rates was not statistically significant $(p=0.12)$.

Urine was centrifuged within $24 \mathrm{~h}$ of collection and the supernatant stored at $-80^{\circ} \mathrm{C}$. Urine was analyzed by a single laboratory using consistent methodology throughout the study. Ten microliters of urine was immunoblotted using nonreducing Laemmli buffer, 4-15\% gradient, polyacrylamide gels (Bio-Rad), and primary antibodies (1:1000; Antibody Shop, Gentofte, Denmark). Recombinant human NGAL was used to create a standard curve of immunoblots $(0.2-5 \mathrm{ng})$, reproducible to $0.4 \mathrm{ng} / \mathrm{lane}$ with an intra- and inter-assay variation $<5 \%$. Immunoreactivity was confirmed using polyclonal antibodies. The assay yielded discrete UNGAL concentrations of $2 \mathrm{ng} / \mathrm{mL}, 5$ $\mathrm{ng} / \mathrm{mL}, 10 \mathrm{ng} / \mathrm{mL}, 15 \mathrm{ng} / \mathrm{mL}, 20 \mathrm{ng} / \mathrm{mL}$, etc.

Statistical analysis. Mean, median, 95th, and 99th quantiles of pooled UNGAL samples were determined collectively and separately for male and female infants. The Maritz-Jarrett estimate (26) of SE of median values was calculated and compared with an estimate derived from bootstrap simulations (S-Plus software, version 6.2, Insightful Corporation, Seattle, WA). Because these two estimates usually agreed closely, only the bootstrap estimates are reported. Under the assumption that UNGAL concentration has an underlying log-normal distribution, we also report geometric means and SDs. We explored the relationships between UNGAL concentration and gender, gestational age, postnatal age, study period, and collection site using repeatedmeasures mixed-effects regression models. Regression coefficients from these models, indicating the rate of change in $\log (\mathrm{UNGAL})$ with covariates, correspond to percent changes in UNGAL (27). Repeated measures mixed-effect models using [SCreat] as the dependent variable and postnatal age and gender as covariates were also constructed to examine how [SCreat] changed over time.

\section{RESULTS}

Patient characteristics. The study sample is characterized in Table 1. There were no significant differences between males and females.

UNGAL quantiles. The median, 25th, 75th, and 95th quantiles, and range of pooled UNGAL concentrations were 5 $\mathrm{ng} / \mathrm{mL}, 2 \mathrm{ng} / \mathrm{mL}, 10 \mathrm{ng} / \mathrm{mL}, 50 \mathrm{ng} / \mathrm{mL}$, and $2-150 \mathrm{ng} / \mathrm{mL}$, respectively. The pooled geometric mean and mean +2 SDs for UNGAL values were 6.5 and $54.5 \mathrm{ng} / \mathrm{mL}$, respectively. Table 2 provides the median, $95 \%$ CI, and 95th and 99th percentiles of pooled UNGAL concentrations as well as UNGAL concentrations by gender. UNGAL concentrations

Table 1. Patient characteristics

\begin{tabular}{lcc}
\hline & $\begin{array}{c}\text { Males } \\
(N=30), \%\end{array}$ & $\begin{array}{c}\text { Females } \\
(N=20), \%\end{array}$ \\
\hline Ethnicity & & \\
Caucasian & 23.3 & 35 \\
African-American & 33.3 & 30 \\
Hispanic & 40 & 30 \\
Asian & 3.3 & 5 \\
$\quad$ Total & $100 \%$ & $100 \%$ \\
Reason for delivery & & \\
$\quad$ Pre-eclampsia & 30 & 30 \\
$\quad$ Preterm labor & 20 & 10 \\
$\quad$ Nonreassuring fetal status & 20 & 20 \\
$\quad$ PPROM-chorioamnionitis & 16.7 & 25 \\
Placental abruption & 13.3 & 15 \\
$\quad$ Total & $100 \%$ & $100 \%$ \\
Gestational age (wk), mean \pm & $29.5 \pm 1.6$ & $29.4 \pm 1.7$ \\
$\quad$ standard deviation & & \\
Birth weight (g), mean \pm & $1236 \pm 158$ & $1122 \pm 179$ \\
$\quad$ standard deviation & & \\
5-min Apgar $<5$ & 0 & 0 \\
\hline
\end{tabular}


Table 2. Median, 95th and 99th percentile values of UNGAL pooled by gender

\begin{tabular}{clcc}
\hline $\begin{array}{c}\text { Subjects }(N), \\
\text { urine samples }(n)\end{array}$ & \multicolumn{1}{c}{ Parameter } & $\begin{array}{c}\text { UNGAL } \\
(\mathrm{ng} / \mathrm{mL})\end{array}$ & 95\% CI* \\
\hline All subjects $(N=50)$, & Median & 5 & $4.7,5.4$ \\
$(n=706)$ & 95th percentile & 50 & $33.9,82.2$ \\
& 99th percentile & 120 & $92.2,143.0$ \\
Males $(N=30)$, & Median & 5 & $4.8,5.2$ \\
$(n=457)$ & 95th percentile & 20 & $16.9,26.0$ \\
& 99th percentile & 40 & $25.4,55.4$ \\
Females $(N=20)$, & Median & 10 & $9.0,11.1$ \\
$(n=249)$ & 95th percentile & 100 & $83.5,116.3$ \\
& 99th percentile & 135.2 & $120.4,148.4$ \\
\hline
\end{tabular}

* CIs for quantiles were computed using a bootstrap estimate of the standard error of the quantile estimate, based on 1000 simulations.

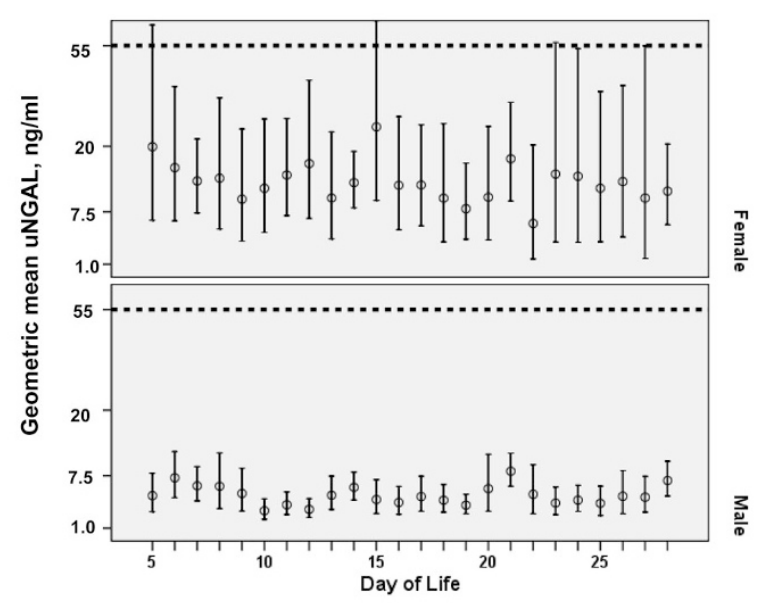

Figure 1. Geometric mean of daily UNGAL, by gender, days 4-28. Error bars represent daily $95 \%$ CI of geometric mean. Dotted line represents 2 SDs from geometric mean of all pooled UNGAL values, days 4-28.

were lower and less variable in males than in females, as shown in Figure 1. Within gender, UNGAL quantiles were similar across study period and location.

Regression models. In multiple linear, mixed-effects regression models incorporating gestational age, gender, collection location, study period, and postnatal age within subject, UNGAL concentration in VLBW infants with uncomplicated clinical courses declined by $1.33 \%$ (95\% CI: -2.39 , $-0.27 ; p=0.013$ ) for each day of postnatal age and declined by $17.8 \%$ for each week of increasing gestational age $(95 \%$ CI: $-28.6,-7.51 ; p=0.002$; see Table 3). Declines of similar magnitude were noted in separate models for males and females, although CIs were wider and $p$-values less significant for females. Male UNGAL concentrations were $79 \%$ lower than female concentrations $(p<0.0001)$. There were no significant gestational age-postnatal age and genderpostnatal age interactions when these terms were introduced into the models.

Serum creatinine. Mean \pm SD pooled [SCreat] between postnatal days $4-28(0.76 \pm 0.26 \mathrm{mg} / \mathrm{dL})$ differed significantly between males $(0.68 \pm 0.24 \mathrm{mg} / \mathrm{dL})$ and females $(0.77 \pm 0.21 \mathrm{mg} / \mathrm{dL}, p=0.004)$. In a repeated measures mixed-effects model controlling for gender, [SCreat] declined by $0.02 \pm 0.001 \mathrm{mg} / \mathrm{dL}$ per day in the interval $4-28 \mathrm{~d}$ postnatal age. In this model, gender had no significant influence on the decline of [SCreat], suggesting that the apparent difference in mean [SCreat] between males and females was due to higher values in selected individuals rather than gender, per se.

\section{DISCUSSION}

This is the third report of UNGAL concentrations in VLBW infants $(25,28)$. Compared with previous reports, the strengths of this study are a larger patient population, the daily urine collections for the first month of life in a portion of the study population, and exclusion of VLBW infants with complicated courses. This report provides normative UNGAL concentrations, further refining the preliminary data from a study of 22 infants with uncomplicated clinical courses that we previously reported (25). No patients $<26$-wk gestation or birth weight $\leq 750 \mathrm{~g}$ in this sample had uncomplicated clinical courses. Thus, these normative data may not be applicable to the extremely premature or extremely low birth weight infant. These normative data are similar to normative UNGAL concentrations in children and adults $(16,18,21,29,30)$.

In this and our previous study (25), UNGAL is expressed as a concentration rather than per unit of urine creatinine. The existing NGAL literature provides no clear guidance about whether to normalize UNGAL results with urinary creatinine; we found no evidence that normalization improves the interpretability of UNGAL. Normalization requires the collection of additional urine and adds cost to the study. In selected cases, we explored whether unexpectedly high UNGAL values could be explained by unusually concentrated urine, as determined by normalization with urine creatinine, but we found no consistent relationship between UNGAL concentration and urine creatinine concentration that would account for the unexpected UNGAL levels. In work with adults, we have found that the differences in UNGAL levels between normal renal function and intrinsic renal failure are so dramatic that normalization does not enhance specificity (29).

We used mixed-effects linear regression models to examine the relationship between UNGAL concentration and gestational age at birth, chronological age, and gender, under the assumption that UNGAL concentration has a log-normal distribution. These models account for the within-subject correlations across chronological age. They indicate that UNGAL concentrations decline significantly with increases in both gestational and chronological age, a finding that is consistent with the early expression of NGAL and its role in renal development. Such declines were not seen in similar models in our preliminary report, perhaps because this report included fewer patients and fewer urine samples per patient and provided insufficient power to detect such declines (25).

Significant differences in UNGAL concentrations between males and females were noted in pooled univariate analyses (Table 2), in pooled day-by-day data (Fig. 1), and in regression models (Table 3). The reason for these differences is not yet known. Occasional findings of diffuse, nonspecific antibody staining throughout a wide range of molecular weights in western blots of urine samples obtained from females sug- 
Table 3. Percent change in UNGAL value per unit change in value of parameter*

\begin{tabular}{cccc}
\hline Parameter & Change in UNGAL $\dagger$ & $95 \%$ CI for percent change & $p$ value \\
\hline Day of life (days 4-30) & $-1.33 \% / \mathrm{d}$ & $-2.39,-0.27$ & 0.013 \\
Males only $\$$ & $-1.05 \% / \mathrm{d}$ & $-2.28,0.19$ & 0.098 \\
Females only $\$$ & $-1.60 \% / \mathrm{d}$ & $-3.48,0.28$ & 0.098 \\
Gestational age (wk) & $-17.8 \% / \mathrm{wk}$ & $-28.6,-7.51$ & 0.002 \\
Males only $\$$ & $-14.7 \% / \mathrm{wk}$ & $-24.8,-4.51$ & 0.009 \\
Females only & $-22.6 \% / \mathrm{wk}$ & $-42.7,-2.34$ & 0.044 \\
Male gender (main effect) & $-79 \%$ & $-16.4,-112$ & $<0.0001$ \\
\hline
\end{tabular}

$*$ Based on regression coefficients from linear mixed repeated-measures model as follows: Fixed element: $\log (\mathrm{UNGAL})=$ gender + gestational age + day of life + study period $\$+$ study location; random element: $\log ($ UNGAL) $=$ day of life within infant, where Study period 1 is from September 2005 to June 2006 and Study period 2 is from March 2007 to March 2008; locations are MSCHONY and AECOM.

$\dagger$ Percent change is equivalent to $100 \times$ (estimate of regression coefficient)/per unit of parameter.

$\$$ Main effect gender term was removed from gender-separate models. When included (as above*), it indicates that UNGAL values for males are $79 \%$ lower than those of females, controlling for day of life, gestational age, study period, and study location.

gested that those urine samples may have been contaminated by stool or vaginal secretions, potentially explaining the erratically elevated UNGAL concentrations and increased variance in females compared with males. To explore this hypothesis we performed "spot checks" on several urine samples: we measured urinary myeloperoxidase to test for sample contamination with neutrophils. Analysis of urine samples from a female with visible evidence of contamination and unusually elevated UNGAL concentrations were associated with elevated myeloperoxidase levels. In contrast, no myeloperoxidase or signs of visible contamination in urine samples were found in males with uncomplicated clinical courses.

Clearly, spot checks do not settle whether the female-male difference is due to contamination, to some biologic difference in renal function between the sexes, or to a combination of the two. The significant effect of gender in the mixed-effects regression analyses indicates that the higher level and increased variability of UNGAL in females is either related to gender itself or, alternatively, that sample contamination is common enough in females to confound the gender term. Concurrent [SCreat] measurements, which would not be subject to contamination, also seemed to indicate that males and females had differing renal function; however, in contrast to UNGAL, this difference disappeared in the mixed-effect regression models, suggesting that it was a property of individual babies and unrelated to gender. Further investigation into the source of the observed gender differences is needed. For now we would emphasize that, given the practical difficulties of urine collection in preterm newborns, male and female babies deserve separate sets of UNGAL norms.

Finally, the question arises whether or not the differences between males and females, as well as those observed across the gestational and chronological age ranges of the study, are clinically relevant. Our preliminary examination of UNGAL concentrations from infants who experienced complications suggests that these concentrations are orders of magnitude higher than those from infants without complications. Thus, variations by gender, gestational age, and postnatal age, although biologically interesting, may be unimportant if the purpose of UNGAL analysis is to provide an early marker for renal impairment.

In conclusion, in this study of 50 VLBW infants with uncomplicated courses and without risk factors for renal im- pairment, we have established the reference range of UNGAL concentration. These normative data are similar to normative UNGAL concentrations for older children and adults. Because we identified no patients $<26$-wk gestation or birth weight $\leq 750 \mathrm{~g}$ with uncomplicated clinical courses, our reference range may not be applicable to such infants. The higher values and increased variability of UNGAL concentrations in urine from females may be due to sample contamination; however, further investigation is required to explore possible biologic explanations for this finding.

Acknowledgments. Assistance in collecting daily urine samples was provided by Allison R. Polland, BS, Kristin M. Capone, BS, and Patrick L. Scarborough, BS. Shlomo Kuperman, BS, and Matthew O'Rourke, MD, provided technical help and assisted in data entry.

\section{REFERENCES}

1. Choker G, Gouyon JB 2004 Diagnosis of acute renal failure in very preterm infants. Biol Neonate 86:212-216

2. Miall LS, Henderson MJ, Turner AJ, Brownlee KG, Brocklebank JT, Newell SJ, Allgar VL 1999 Plasma creatinine rises dramatically in the first 48 hours of life in preterm infants. Pediatrics 104:e76

3. Guignard JP, Drukker A 1999 Why do newborn infants have a high plasma creatinine? Pediatrics 103:e49

4. Gallini F, Maggio L, Romagnoli C, Marrocco G, Tortorolo G 2000 Progression of renal function in preterm neonates with gestational age $<$ or $=32$ weeks. Pediatr Nephrol 15:119-124

5. Toth-Heyn P, Drukker A, Guignard JP 2000 The stressed neonatal kidney: from pathophysiology to clinical management of neonatal vasomotor nephropathy. Pediatr Nephrol 14:227-239

6. Gouyon JB, Guignard JP 2000 Management of acute renal failure in newborns Pediatr Nephrol 14:1037-1044

7. Coulthard MG, Vernon B 1995 Managing acute renal failure in very low birthweight infants. Arch Dis Child Fetal Neonatal Ed 73:F187-F192

8. Schmidt-Ott KM, Mori K, Kalandadze A, Li JY, Paragas N, Nicholas T, Devarajan $\mathrm{P}$, Barasch J 2006 Neutrophil gelatinase-associated lipocalin-mediated iron traffic in kidney epithelia. Curr Opin Nephrol Hypertens 15:442-449

9. Schmidt-Ott KM, Mori K, Li JY, Kalandadze A, Cohen DJ, Devarajan P, Barasch J 2007 Dual action of neutrophil gelatinase-associated lipocalin. J Am Soc Nephrol 18:407-413

10. Goetz DH, Holmes MA, Borregaard N, Bluhm ME, Raymond KN, Strong RK 2002 The neutrophil lipocalin NGAL is a bacteriostatic agent that interferes with siderophore-mediated iron acquisition. Mol Cell 10:1033-1043

11. Mishra J, Ma Q, Prada A, Mitsnefes M, Zahedi K, Yang J, Barasch J, Devarajan P 2003 Identification of neutrophil gelatinase-associated lipocalin as a novel early urinary biomarker for ischemic renal injury. J Am Soc Nephrol 14:2534-2543

12. Devarajan P, Mishra J, Supavekin S, Patterson LT, Steven Potter S 2003 Gene expression in early ischemic renal injury: clues towards pathogenesis, biomarker discovery, and novel therapeutics. Mol Genet Metab 80:365-376

13. Mishra J, Mori K, Ma Q, Kelly C, Barasch J, Devarajan P 2004 Neutrophil gelatinase-associated lipocalin: a novel early urinary biomarker for cisplatin nephrotoxicity. Am J Nephrol 24:307-315 
14. Mishra J, Mori K, Ma Q, Kelly C, Yang J, Mitsnefes M, Barasch J, Devarajan P 2004 Amelioration of ischemic acute renal injury by neutrophil gelatinase-associated lipocalin. J Am Soc Nephrol 15:3073-3082

15. Mishra J, Ma Q, Kelly C, Mitsnefes M, Mori K, Barasch J, Devarajan P 2006 Kidney NGAL is a novel early marker of acute injury following transplantation. Pediatr Nephrol 21:856-863

16. Mishra J, Dent C, Tarabishi R, Mitsnefes MM, Ma Q, Kelly C, Ruff SM, Zahedi K, Shao M, Bean J, Mori K, Barasch J, Devarajan P 2005 Neutrophil gelatinaseassociated lipocalin (NGAL) as a biomarker for acute renal injury after cardiac surgery. Lancet 365:1231-1238

17. Wagener G, Jan M, Kim M, Mori K, Barasch JM, Sladen RN, Lee HT 2006 Association between increases in urinary neutrophil gelatinase-associated lipocalin and acute renal dysfunction after adult cardiac surgery. Anesthesiology 105:485491

18. Parikh CR, Jani A, Mishra J, Ma Q, Kelly C, Barasch J, Edelstein CL, Devarajan P 2006 Urine NGAL and IL-18 are predictive biomarkers for delayed graft function following kidney transplantation. Am J Transplant 6:1639-1645

19. Trachtman H, Christen E, Cnaan A, Patrick J, Mai V, Mishra J, Jain A, Bullington N, Devarajan P; Investigators of the HUS-SYNSORB Pk Multicenter Clinical Trial 2006 Urinary neutrophil gelatinase-associated lipocalcin in D+HUS: a novel marker of renal injury. Pediatr Nephrol 21:989-994

20. Brunner HI, Mueller M, Rutherford C, Passo MH, Witte D, Grom A, Mishra J, Devarajan P 2006 Urinary neutrophil gelatinase-associated lipocalin as a biomarker of nephritis in childhood-onset systemic lupus erythematosus. Arthritis Rheum 54:2577-2584

21. Hirsch R, Dent C, Pfriem H, Allen J, Beekman RH 3rd, Ma Q, Dastrala S, Bennett M, Mitsnefes M, Devarajan P 2007 NGAL is an early predictive biomarker of contrast-induced nephropathy in children. Pediatr Nephrol 22:2089-2095
22. Yang J, Mori K, Li JY, Barasch J 2003 Iron, lipocalin, and kidney epithelia. Am J Physiol Renal Physiol 285:F9-F18

23. Gwira JA, Wei F, Ishibe S, Ueland JM, Barasch J, Cantley LG 2005 Expression of neutrophil gelatinase-associated lipocalin regulates epithelial morphogenesis in vitro. J Biol Chem 280:7875-7882

24. Yang J, Goetz D, Li JY, Wang W, Mori K, Setlik D, Du T, Erdjument-Bromage H, Tempst P, Strong R, Barasch J 2002 An iron delivery pathway mediated by a lipocalin. Mol Cell 10:1045-1056

25. Parravicini E, Lorenz JM, Nemerofsky SL, O'Rourke M, Barasch J, Bateman D 2009 Reference range of urinary neutrophil gelatinase-associated lipocalin in very low-birth-weight infants: preliminary data. Am J Perinatol 26:437-440

26. Wilcox RR 1997 Introduction to Robust Estimation and Hypothesis Testing. Academic Press, San Diego, CA, 296 pp

27. Cole TJ 2000 Sympercents: symmetric percentage differences on the $100 \log$ (e) scale simplify the presentation of log transformed data. Stat Med 19:3109-3125

28. Lavery AP, Meinzen-Derr JK, Anderson E, Ma Q, Bennett MR, Devarajan P, Schibler KR 2008 Urinary NGAL in premature infants. Pediatr Res 64:423-428

29. Mori K, Lee HT, Rapoport D, Drexler IR, Foster K, Yang J, Schmidt-Ott KM, Chen X, Li JY, Weiss S, Mishra J, Cheema FH, Markowitz G, Suganami T, Sawai K, Mukoyama M, Kunis C, D'Agati V, Devarajan P, Barasch J 2005 Endocytic delivery of lipocalin-siderophore-iron complex rescues the kidney from ischemia-reperfusion injury. J Clin Invest 115:610-621

30. Zappitelli M, Washburn KK, Arikan AA, Loftis L, Ma Q, Devarajan P, Parikh CR, Goldstein SL 2007 Urine neutrophil gelatinase-associated lipocalin is an early marker of acute kidney injury in critically ill children: a prospective cohort study. Crit Care 11:R84 